\title{
A case of severe preeclampsia presenting as acute pulmonary oedema
}

\section{Sumangala Devi, Bindu Vijay Kumar*}

\author{
Department of Obstetrics \& Gynecology, Government Medical College, Kozhikode, Kerala, India
}

Received: 12 December 2015

Revised: 19 January 2016

Accepted: 23 January 2016

\section{*Correspondence:}

Dr. Bindu Vijay Kumar,

E-mail: bindu.vk@gmail.com

Copyright: (c) the author(s), publisher and licensee Medip Academy. This is an open-access article distributed under the terms of the Creative Commons Attribution Non-Commercial License, which permits unrestricted non-commercial use, distribution, and reproduction in any medium, provided the original work is properly cited.

\begin{abstract}
Pulmonary edema refers to an excessive accumulation of fluid in the pulmonary interstitial and alveolar spaces. It may occur in low risk pregnancies but one very important predisposing factor is association with preeclampsia. We are reporting a case of severe preeclampsia presenting as acute pulmonary oedema. 21 year old primi, a known case of gestational hypertension on drugs had pedal edema which was progressively increasing. She was admitted at $29 \mathrm{w} 5 \mathrm{~d}$ as her BP was still high. Since her preeclampsia profile was normal and her BP was controlled she was continued on conservative management. After 2 days she developed cough, tachypnoea and tachycardia with clinical findings suggestive of $\mathrm{A} / \mathrm{c}$ pulmonary oedema. Shifted to HDU and started on diuretics and other symptomatic management. After 1 hour as patient's condition was worsening with O2 saturation fall, decided for LSCS + elective post operative ventilatory support. LSCS done showed evidence of Grade 3 abruption with couvelaire changes on uterus. Baby weighed $1.24 \mathrm{~kg}$, severely asphyxiated, died after 3 days. Patient was put on ventillatory support and she improved postoperatively. Acute pulmonary oedema in pregnant women is a life-threatening event. Prompt diagnosis and management is very important for the survival of the patient.
\end{abstract}

Keywords: Preeclampsia, Pulmonary oedema, Endothelial damage, Ventilation

\section{INTRODUCTION}

Pulmonary edema complicates around $0.05 \%$ of low-risk pregnancies but may develop in up to $2.9 \%$ of pregnancies complicated by preeclampsia Sibai et al. ${ }^{1}$

Pulmonary edema is infrequently encountered in patients with severe pre-eclampsia without associated medical, surgical or obstetric complications (1-2\%). One such case is reported here.

Acute pulmonary oedema in pregnant women is a lifethreatening event.

This is due to the superimposed issues of the physiological changes of pregnancy and the presence of the fetus, as well as the contributory effect of poorly understood pathophysiology of pregnancy-related disease such as pre-eclampsia which is associated with significant morbidity and mortality for mother and baby.

Persisting hypoxemia is particularly concerning and justifies intensive care. Death has been reported in around $10 \%$ of cases often reflecting multiorgan failure. ${ }^{2}$ Prompt delivery is the safest option for the lady \& her fetus when there is evidence of pulmonary oedema irrespective of gestational age.

\section{CASE REPORT}

21 year old primi booked case in Institute of Maternal and Child Health, Government Medical College, Kozhikode, Kerala was detected to have gestational hypertension at 28 weeks of gestation and started on alpha methyl dopa (250 mg) QID. She had pedal edema which was progressively increasing. 
She was admitted at 29w5d as her BP was still high.

She gives h/o Preeclampsia for her mother and twin sister.

\section{On examination}

There was pallor and bilateral pitting pedal edema.

All her general and systemic examination findings were normal.

There was no IUGR.

\section{Investigations}

Anaemia (Hb-9.5gm\%) \& urine albumin was trace.

Platelet count, LFT\& RFT was normal.

As there was no features of preeclampsia dose of antihypertensive was increased and decided on continuing pregnancy.

After 2 days of admission (30 wks) she started developing facial puffiness and abdominal wall edema. BP was controlled.

Investigations - Elevated blood urea \& 24 hour urine protein of $6 \mathrm{~g}, \mathrm{Hb}-9.5 \mathrm{gm}$ other inv normal.

Next day morning (30 weeks 1 day) she complained of irritating cough on lying down.

\section{On examination}

There was tachycardia, tachypnoea. BP was 150/100.

$\mathrm{SpO}_{2}-96 \%$ with $\mathrm{O}_{2}$ (as $\mathrm{Spo} 2$ was coming down without $\mathrm{O}_{2}$ ). Vulval edema was present. Chest showed bilateral basal crepitations.

\section{Diagnosis- acute pulmonary edema}

Shifted to HDU and started on diuretics and other symptomatic management. Decision for termination of pregnancy was taken. Bishop score was very unfavourable, so started with Foley EAS+PGE1 induction.

But after 1 hour as patient condition was worsening with $\mathrm{O} 2$ saturation fall, decided for LSCS + elective postoperative ventilatory support.

LSCS done showed evidence of Grade 3 abruption with couvelaire changes on uterus. Baby weighed $1.24 \mathrm{~kg}$, severely asphyxiated, died after 3 days.
Post operatively she was put on ventilator support and slowly weaned. As tachypnoea was persisting CXR was done which showed features of consolidation. It was managed with antibiotics. Patient got better and was discharged on day 13 .

\section{DISCUSSION}

Acute pulmonary oedema may be caused by a variety of perturbations of any one of the key determinants of cardiovascular function and fluid flow into the pulmonary interstitium. The causes of pulmonary edema are often multifactorial. According to the Starling equation, any factor that results in a reduction in colloid osmotic pressure (or in the colloid osmotic pressure/pulmonary capillary wedge pressure gradient), an increase in capillary permeability, or an increase in intravascular hydrostatic pressure will lead to extravasation of fluid from the vasculature and predispose to the development of pulmonary oedema. ${ }^{2}$

It is now recognised that not only is fluid accumulation and retention, a mechanism for acute pulmonary oedema, but so too is fluid redistribution from the systemic circulation to the pulmonary circulation due to venoconstriction or vasoconstriction in a person who is euvolaemic. ${ }^{3,4}$ Therapies for the treatment of acute pulmonary oedema reverse one or more of these factors, with re-absorption of pulmonary oedema both a passive and an active process. ${ }^{5}$

Frequently, more than one risk factor is present, with iatrogenic fluid administration a major preventable factor. 6 Specific aetiologies causing acute pulmonary oedema have an increased likelihood of occurring during specific time periods; for example, tocolytic therapy in the antenatal period and fluid overload in combination with pre-eclampsia in the postpartum period. ${ }^{7}$

Pre-eclampsia is a multisystem major cardiovascular disease of pregnancy with hypertension as its main clinical manifestation. ${ }^{8,9}$ Acute pulmonary oedema, which signifies severe disease, is a leading cause of death in women with pre-eclampsia and is a frequent cause for admission to an intensive care unit. ${ }^{8,9,12}$ Pulmonary oedema may occur in up to approximately $3 \%$ of women with pre-eclampsia, with $70 \%$ of cases occurring after birth. The reduction in colloid osmotic pressure after delivery may result from excessive blood loss, fluid shifts secondary to increased capillary permeability (especially in preeclamptic pregnancies), or excessive crystalloid infusion. Such changes help to explain at least in part why $70-80 \%$ of cases of pulmonary edema in the setting of preeclampsia develop after delivery. ${ }^{13,14}$

Only $30 \%$ of cases of pulmonary edema in the setting of preeclampsia occur before delivery. ${ }^{13}$ The vast majority (90\%) of such patients have underlying chronic hypertension, and they are more likely to be multiparous and of advanced maternal age. ${ }^{13}$ An additional feature 
that may predispose to the development of pulmonary edema in the setting of preeclampsia is an increase in capillary leak and capillary fluid extravasation secondary to vascular endothelial damage.

\section{Diagnosis}

Pulmonary edema is a clinical diagnosis characterized by worsening dyspnea and orthopnea along with signs of respiratory compromise (tachypnea, auditory crackles and rales, hypoxemia).

Arterial blood gas and chest x-ray may assist in the diagnosis.

In select patients, electrocardiography, echocardiography, spiral CT imaging, ventilation/perfusion scan, or pulmonary arteriography may be necessary to exclude other causes of cardiopulmonary compromise, such as pulmonary embolism, pneumonia, and cardiomyopathy.

Another confounding factor is magnesium sulfate, which is often administered to preeclamptic women for seizure prophylaxis.

It is also associated with excessive fluid administration and disease severity, including the presence of haemolysis, elevated liver enzymes and low platelets (HELLP), and eclampsia. ${ }^{16}$ In addition to the usual management goals of stabilising the woman and treating the acute pulmonary oedema, consideration needs to be given to delivery of the fetus if acute pulmonary oedema occurs in the antenatal period.

In a study of 37 cases of pre-eclampsia, Sibai et al reported an incidence of pulmonary edema in $2.9 \%$ patients; $30 \%$ of these cases developed pulmonary edema antenatally, whilst $70 \%$ developed it after delivery, within an average time of 71 hours. ${ }^{1}$ The mechanisms responsible for this increased incidence in the postpartum period are recently reviewed by Benedetti et all and Hankins et al, and are related to delayed post-partum mobilisation of extracellular fluids. ${ }^{15,16}$

\section{The management of hypertensive acute pulmonary oedema in pregnancy}

\section{Immediate management}

The occurrence of acute pulmonary oedema in a hypertensive pregnant or recently pregnant woman is a medical emergency and should trigger an emergency response. Treatment aimed at rapidly assembling an experienced team of staff (level 3 evidence). Further deterioration may occur, leading to cardiac arrest, and staff should be prepared to institute advanced life support and consider peri-mortem caesarean section. Transthoracic echocardiography can assist in differentiating a low cardiac output from a high cardiac output state, as well as exclude other important causes of acute pulmonary oedema.

Despite the risks of aspiration, non-invasive ventilation should be tried as the initial technique before tracheal intubation, as it provides increased inspired oxygen concentration, displaces fluid from the alveoli into the pulmonary and subsequently systemic circulation, decreases the work of breathing, and decreases the need for tracheal intubation (level 1++ evidence). The use of non-invasive ventilation also avoids the complications associated with tracheal intubation in pregnant or recently pregnant women who are hypertensive, such as intracerebral haemorrhage. Mechanical ventilation strategies incorporating the known cardiorespiratory and metabolic changes of pregnancy need to be considered when ventilating the lungs of a pregnant or recently pregnant woman, as well as the lung protective strategies of low tidal volumes and low peak pressures.

Avoidance of aortocaval compression is essential.

Urgent reduction of critically high blood pressure with an intravenous antihypertensive agent is necessary. Nitroglycerin (glyceryl trinitrate) is recommended as the drug of choice in pre-eclampsia associated with pulmonary oedema. Reduction in systolic and diastolic blood pressure should occur at a rate of approximately 30 $\mathrm{mmHg}$ over 3-5 min followed by slower reductions to blood pressures of approximately $140 / 90 \mathrm{mmHg}$.

Intravenous furosemide (bolus $20-40 \mathrm{mg}$ over $2 \mathrm{~min}$ ) is used to promote venodilation and diuresis, with repeated doses of 40-60 mg after approximately $30 \mathrm{~min}$ if there is an inadequate diuretic response (maximum dose 120 $\left.\mathrm{mg} \cdot \mathrm{h}^{-1}\right)$.

\section{Long-term management}

Women who suffer from severe pre-eclampsia and experience acute pulmonary oedema are at increased risk of cardiovascular complications in later life, including hypertension, ischaemic heart disease, stroke and renal disease. They should be closely monitored with control of blood pressure until resolution of the initial disease process and then followed up regularly, with observation for the long-term complications of the disease. Angiotensin-converting enzymes, whilst contraindicated in pregnancy, are safe to use in the postpartum period. Risk reduction strategies should be offered, such as weight reduction and smoking cessation programs, dietary modification, encouragement of regular exercise and control of hypertension.

\section{CONCLUSION}

Acute pulmonary oedema is an indicator of significant morbidity and may lead to mortality in pregnant women. It is paramount to identify the at-risk patient, recognise signs of critical illness and manage these women with a 
skilled multidisciplinary team. Risk reduction strategies should include an emphasis on the importance of fluid balance and recording regular clinical observations. Appropriate long-term follow-up is necessary to reduce the chance of further complications in later life. Finally, the use of transthoracic echocardiography should be encouraged, both as an educational tool and to aid diagnosis and management.

Funding: No funding sources Conflict of interest: None declared

Ethical approval: The study was approved by the Institutional Ethics Committee

\section{REFERENCES}

1. Sibai BM, Mabie BC, Harvey CJ, Gonzalez AR. Pulmonary edema in severe preeclampsia-eclampsia: analysis of thirty-seven consecutive cases. American Journal of Obstetrics and Gynecology. 1987;156:1174-9.

2. Berne R, Levy M. Cardiovascular Physiology, 1st edn. St.Louis: Mosby Year Book, Inc. 1992.

3. Cotter G, Metra M, Milo-Cotter O, Dittrich HC, Gheorghiade M. Fluid overload in acute heart failure--re-distribution and other mechanisms beyond fluid accumulation. European Journal of Heart Failure. 2008;10:165-9.

4. Picano E, Gargani L, Gheorghiade M. Why, when and how to assess pulmonary congestion in heart failure: pathophysiological, clinical, and methodological implications. Heart Failure Review. 2010;15:63-72.

5. Colmenero RM, Fernandez ME, Garcia DM, Rojas M, Lozano L, Poyatos ME. Current concepts of pathophysiology, monitoring and resolution of pulmonary edema. Medicine Intensiva. 2006;30:32230.

6. Thornton CE, von Dadelszen P, Makris A, Tooher JM, Ogle RF, Hennessy A. Acute pulmonary oedema as a complication of hypertension during pregnancy. Hypertension in Pregnancy. 2011;30:169-79.

7. Nassar AH, Aoun J, Usta IM. Calcium channel blockers for the management of preterm birth: a review. American Journal of Perinatology. 2011;28:57-66.

8. Lowe SA, Brown MA, Dekker GA. Guidelines for the management of hypertensive disorders of pregnancy 2008. Australian and New Zealand Journal of Obstetrics and Gynaecology. 2009;49:242-6.

9. Royal College of Obstetricians and Gynaecologists. The management of severe preeclampsia/eclampsia. Guideline no. 10(A). London: RCOG. 2006.

10. Duley L, Williams J, Henderson-Smart DJ. Plasma volume expansion for treatment of pre-eclampsia. Cochrane Database of Systematic Reviews. 1999;4:CD001805.

11. Ganzevoort W, Rep A, Bonsel GJ. A randomised controlled trial comparing two temporising management strategies, one with and one without plasma volume expansion, for severe and early onset preeclampsia. British Journal of Obstetrics and Gynaecology. 2005;112:1358-68.

12. Sriram S, Robertson MS. Critically ill obstetric patients in Australia: a retrospective audit of 8 years' experience in a tertiary intensive care unit. Critical Care and Resuscitation. 2008;10:120-4.

13. Easterling TR, Benedetti TJ. Pre-eclampsia. A hyperdynamic disease model. American Journal of Obstetrics and Gynecology. 1989;160:1447-53.

14. Dennis A, Castro C, Simmons S, Carr C, Permezel M, Royse C. Left ventricular systolic and diastolic function and structure in women with untreated preeclampsia. Pregnancy Hypertension. 2010;1:S1-41.

15. Benedetti TJ, Kates R, Milliams V. Hemodynamic observations in severe pre-eclampsia complicated by pulmonary edema. Amer. J. Obstet. \& Gynaecol. 1985;152:330-4.

16. Hankins GDV, Wendel GD, Cunningham FG, Leveno KJ. Longitudinal evaluation of hemodynamic changes in eclampsia. Amer. J. Obstet. \& Gynaecol. 1984;150:506-12.

Cite this article as: Devi DS, Kumar BJ. A case of severe preeclampsia presenting as acute pulmonary oedema. Int J Reprod Contracept Obstet Gynecol 2016;5:899-902. 